\title{
Inflammation marker and risk of pancreatic cancer: a nested case-control study within the EPIC cohort
}

\begin{abstract}
BACKGROUND: Established risk factors for pancreatic cancer include smoking, long-standing diabetes, high body fatness, and chronic pancreatitis, all of which can be characterised by aspects of inflammatory processes. However, prospective studies investigating the relation between inflammatory markers and pancreatic cancer risk are scarce.

METHODS: We conducted a nested case-control study within the European Prospective Investigation into Cancer and Nutrition, measuring prediagnostic blood levels of C-reactive protein (CRP), interleukin-6 (IL-6), and soluble receptors of tumour necrosis factor- $\alpha$ (sTNF-RI, R2) in 455 pancreatic cancer cases and 455 matched controls. Odds ratios (ORs) were estimated using conditional logistic regression models.

RESULTS: None of the inflammatory markers were significantly associated with risk of pancreatic cancer overall, although a borderline significant association was observed for higher circulating sTNF-R2 (crude OR $=1.52$ (95\% confidence interval (Cl) 0.97-2.39), highest vs lowest quartile). In women, however, higher sTNF-RI levels were significantly associated with risk of pancreatic cancer (crude OR $=1.97(95 \% \mathrm{Cl} \mid .02-3.79)$ ). For sTNF-R2, risk associations seemed to be stronger for diabetic individuals and those with a higher BMI.

CONCLUSION: Prospectively, CRP and IL-6 do not seem to have a role in our study with respect to risk of pancreatic cancer, whereas sTNF-RI seemed to be a risk factor in women and sTNF-R2 might be a mediator in the risk relationship between overweight and diabetes with pancreatic cancer. Further large prospective studies are needed to clarify the role of proinflammatory proteins and cytokines in the pathogenesis of exocrine pancreatic cancer.
\end{abstract}

British Journal of Cancer (2012) I 06, 1866-1874. doi:10.1038/bjc.2012.172 www.bjcancer.com

Published online 26 April 2012

(c) 2012 Cancer Research UK

Keywords: inflammation; pancreatic cancer; EPIC; CRP; IL-6; TNF receptor

\section{VA Grote', R Kaaks*,I, A Nieters',2, A Tjønneland ${ }^{3}$, J Halkjær ${ }^{3}$, K Overvad ${ }^{4}$, MR Skjelbo Nielsen ${ }^{5}$, MC Boutron-Ruault ${ }^{6,7}$, F Clavel-Chapelon ${ }^{6,7}$, A Racine ${ }^{6,7}$, B Teucher', S Becker ${ }^{1,8}$, T Pischon ${ }^{9}$, H Boeing ${ }^{10}$, A Trichopoulou ${ }^{11,12}$, C Cassapa ${ }^{12}$, V Stratigakou ${ }^{12}$, D Palli ${ }^{13}$, V Krogh ${ }^{14}$, R Tumino ${ }^{15}$, P Vineis ${ }^{16,17}$, S Panico $^{18}$, L Rodríguez $^{19}$, EJ Duell ${ }^{20,21}$, M-J Sánchez ${ }^{21,22}$, M Dorronsoro $^{21,23}$, C Navarro $^{21,24}$, AB Gurrea $^{21,25}$, PD Siersema ${ }^{26}$, P HM Peeters ${ }^{27,28}, \mathrm{~W} \mathrm{Ye}^{29,30}$, M Sund ${ }^{31}$, B Lindkvist ${ }^{32}$, D Johansen ${ }^{33}$, K-T Khaw ${ }^{34}$, N Wareham ${ }^{35}$, NE Allen ${ }^{36}$, RC Travis ${ }^{36}$, V Fedirko ${ }^{37}, \mathbf{M}$ Jenab $^{37}$, DS Michaud ${ }^{38,39}$, S-C Chuang $^{38}$, D Romaguera $^{38}$, HB Bueno-de-Mesquita ${ }^{26,40}$ and S Rohrmann ${ }^{1,41}$}

'Division of Cancer Epidemiology (c020), German Cancer Research Center (DKFZ), Im Neuenheimer Feld 581, Heidelberg 691 20, Germany: ${ }^{2}$ Centre of Chronic Immunodeficiency, CCI Molecular Epidemiology, University Medical Center Freiburg, Breisacher St. 1 I 7, Freiburg 79 I06, Germany; ${ }^{3}$ Institute of Cancer Epidemiology, Danish Cancer Society, Strandboulevarden 49, Copenhagen 2100, Denmark; ${ }^{4}$ Department of Epidemiology, School of Public Health, Aarhus University, Nordre Ringgade I, Aarhus 8000, Denmark; ${ }^{5}$ Center for Cardiovascular Research, Aarhus University Hospital, Hobrovej 18 , Aalborg 9100, Denmark; 'INSERM, Centre for Research in Epidemiology and Population Health, UI0I8, Institut Gustave Roussy, II 4 rue Edouard Vaillant, Villejuif 94805, France; ${ }^{7}$ Paris South University, UMRS 1018 , Villejuif, France; ${ }^{8}$ Institute of Laboratory Medicine, Clinical Chemistry and Molecular Diagnostics, University Hospital Leipzig, Paul-List-Str. 13-15, Leipzig 4103, Germany; ${ }^{9}$ Molecular Epidemiology Group, Max Delbrück Center for Molecular Medicine (MDC), Robert-Rössle-Straße 10, Berlin-Buch 13125, Germany; ${ }^{10}$ Department of Epidemiology, German Institute of Human Nutrition Potsdam-Rehbruecke, Arthur-Scheunert-Allee 1/4/I16, Nuthetal 14558, Germany; "WHO Collaborating Center for Food and Nutrition Policies, Department of Hygiene, Epidemiology and Medical Statistics, University of Athens Medical School, Athens, Greece; ${ }^{12}$ Hellenic Health Foundation, 10-12 Tetrapoleos Street, Athens II 5 27, Greece; ' 3 Molecular and Nutritional Epidemiology Unit, Cancer Research and Prevention Institute - ISPO, Ponte Nuovo, Via delle Oblate n.2, Florence 50 I4I, Italy; ${ }^{14}$ Nutritional Epidemiology Unit, Fondazione IRCCS Istituto Nazionale Tumori, Via Venezian, I, Milano 20133, Italy; ${ }^{15}$ Cancer Registry and Histopathology Unit, 'Civile M.P.Arezzo' Hospital, Via Civile, Ragusa 97 I00, Italy; ${ }^{16}$ School of Public Health, Imperial College London, Norfolk Place, London W2 IPG, UK; ${ }^{17} \mathrm{HuGeF}$ Foundation, Torino, Italy; ${ }^{18}$ Department of Clinical and Experimental Medicine, Federico II University, Corso Umberto I, Naples 80138, Italy; ${ }^{19}$ Public Health and Participation Directorate, Health and Health Care Services Council, Ciriaco Miguel Vigil 9, Asturias 33009, Spain; ${ }^{20}$ Unit of Nutrition, Environment and Cancer, Cancer Epidemiology Research Program, Catalan Institute of Oncology (ICO-IDIBELL), L'Hospitalet de Llobregat, Avda Gran Via 199-203, Barcelona 8907, Spain; ${ }^{2}$ CIBER Epidemiología y Salud Pública (CIBERESP), Barcelona, Spain; ${ }^{22}$ Andalusian School of Public Health, Cuesta del Observatorio 4, Granada 1801 I, Spain; ${ }^{23}$ Public Health Division of Gipuzkoa, Basque Regional Health Department, Avda. Navarra, 4, San Sebastian 200 13, Spain; ${ }^{24}$ Department of Epidemiology, Murcia Regional Health Authority, Ronda de Levante, II, Murcia 30008, Spain; ${ }^{25}$ Navarre Public Health Institute, Polígono de Landaben C/F, Pamplona 31012 , Spain; ${ }^{26}$ Department of

* Correspondence: Dr R Kaaks; E-mail: r.kaaks@dkfz.de

Revised 10 February 2012; accepted 29 March 2012; published online 26 April 2012 
Gastroenterology and Hepatology, University Medical Centre Utrecht, Heidelberglaan 100, Utrecht 3584 CX. The Netherlands; ${ }^{27}$ Jlius Center, University Medical Center Utrecht, Huispost Str. 6.1 31, 3508 GA Utrecht, The Netherlands; ${ }^{28}$ Department of Epidemiology and Biostatistics, School of Public Health, Faculty of Medicine, Imperial College, London, UK; ${ }^{29}$ Department of Medical Epidemiology and Biostatistics, Karolinska Institute, Box 28I, Stockholm 171 77, Sweden; ${ }^{30}$ The Medical Biobank at Umeå University, Umeå, Sweden; ${ }^{31}$ Departments of Surgical and Perioperative Sciences, Surgery and Public Health and Clinical Medicine, Nutrition Research, Umeå University, I A, 9 tr, Kirurgcentrum, 952, Umeå 90I 85, Sweden; ${ }^{32}$ Institute of Medicine, Sahlgrenska Academy, University of Gothenburg, Box 100, Gothenburg 205 02, Sweden; ${ }^{33}$ Department of Surgery, Skåne University Hospital, Lund University, Box 117 , Malmö 205 02, Sweden; ${ }^{34}$ Department of Public Health and Primary Care, University of Cambridge, Robinson Way, Cambridge CB2 OSR, UK; ${ }^{35}$ MRC Epidemiology Unit, Hills Road, Cambridge CB2 OQQ, UK; ${ }^{36}$ Cancer Epidemiology Unit, Nuffield Department of Clinical Medicine, University of Oxford, Old Road Campus, Oxford OX3 7LF, UK; ${ }^{37}$ Nutritional Epidemiology Group, International Agency for Research on Cancer (IARC-WHO), I 50 Cours Albert Thomas, Lyon 69372, France; ${ }^{38}$ School of Public Health, Imperial College, Norfolk Place, London W2 IPG, UK; ${ }^{39}$ Division of Biology and Medicine, Brown University, Providence, RI, USA; ${ }^{40}$ National Institute for Public Health and the Environment (RIVM), PO Box I, Bilthoven 3720 BA, The Netherlands; ${ }^{41}$ Division of Cancer Epidemiology and Prevention, Institute of Social and Preventive Medicine, Hirschengraben 84 , Zurich 8001 , Switzerland

Evidence is accumulating that systemic low-grade chronic inflammation in addition to local inflammation in the pancreas is involved in the pathogenesis of pancreatic cancer (Farrow and Evers, 2002; Whitcomb, 2004; McKay et al, 2008). Research findings pointing to this direction include the documented relationship of pancreatic cancer risk with chronic pancreatitis (Raimondi et al, 2010), as well as with smoking (Lynch et al, 2009; Vrieling et al, 2010), pre-existing and long-standing diabetes mellitus (Huxley et al, 2005), and excess weight (Genkinger et al, 2010), all of which are known or suggestive determinants of lowgrade inflammatory states (Whitcomb, 2004; Kolb and MandrupPoulsen, 2005; Hotamisligil, 2006; Goncalves et al, 2011).

Even though the mechanisms by which chronic inflammation leads to carcinogenesis are not fully understood, it is generally accepted that inflammation results in repeated DNA damage and in the accumulation of genetic defects (McKay et al, 2008). However, proinflammatory cytokines and growth factors are also released in response to the tumour, making it difficult to distinguish between cause and effect in the inflammatory processes (McKay et al, 2008).

Circulating C-reactive protein (CRP) concentration, an acute-phase protein produced in the liver, is increased in pancreatic cancer patients (Barber et al, 1999; Moses et al, 2009; Mroczko et al, 2010), most likely as part of the systemic inflammatory response to the tumour. Interleukin-6 (IL-6) and tumour necrosis factor- $\alpha$ (TNF- $\alpha$ ) are upregulating factors of CRP and have also been shown to be increased in pancreatic cancer patients (Barber et al, 1999; Ebrahimi et al, 2004; Moses et al, 2009; Talar-Wojnarowska et al, 2009; Mroczko et al, 2010). Prospectively, increased levels of CRP have inconsistently been associated with pancreatic cancer risk. To our knowledge, prospective studies on the association of IL- 6 , TNF- $\alpha$, or its receptors with risk of pancreatic cancer are lacking.

We measured prediagnostic concentrations of CRP, IL-6, and soluble TNF receptors (sTNF-R1 and R2) in blood samples of 455 primary exocrine pancreatic cancer cases and 455 individually matched controls within the Prospective Investigation into Cancer and Nutrition (EPIC) as possible reflections of either pancreatic cancer or a metabolic risk factor potentially increasing pancreatic cancer risk by aggravating pancreatic inflammatory disease.

\section{MATERIALS AND METHODS}

\section{Study population}

The European Prospective Investigation into Cancer and Nutrition (EPIC) is a large cohort study conducted in 23 centres in ten European countries (Denmark, France, Germany, Greece, Italy, the Netherlands, Spain, Sweden, and the United Kingdom). Detailed descriptions of study design, population, and baseline data collection of the cohort can be found elsewhere (Haftenberger et al, 2002; Riboli et al, 2002). Briefly, about 370000 women and 150000 men were enroled between 1992 and 2000. Participants provided information on dietary habits and lifestyle factors, and in addition, weight, height, and waist and hip circumferences were measured at baseline. Each participant provided informed consent, and the local ethical review committees approved the EPIC cohort study as well as the current project.

\section{Blood sample collection and storage}

In the seven EPIC core countries (France, Germany, Greece, Italy, the Netherlands, Spain, and the United Kingdom), blood samples were collected at baseline, based on a standardized protocol and aliquoted in plastic straws (plasma, serum, erythrocytes, and buffy coat for DNA). The aliquoted specimens were then stored in a central biorepository in liquid nitrogen $\left(-196^{\circ} \mathrm{C}\right)$. In Sweden, all samples were stored locally in freezers at $-70^{\circ} \mathrm{C}$ and in Denmark in nitrogen vapour $\left(-150^{\circ} \mathrm{C}\right)$. In this study, Norway was excluded because blood samples were only recently collected and very few pancreatic cancer cases have been diagnosed after blood donation.

\section{Follow-up for cancer incidence and vital status}

In six of the participating countries (Denmark, Italy, the Netherlands, Spain, Sweden, and the United Kingdom), follow-up of cancer cases was based on population registries. In the other three countries (France, Germany, and Greece), a combination of methods was used including health insurance records, cancer and pathology registries, and active follow-up through study subjects and their next-of-kin. In all EPIC centres, data on vital status are collected from mortality registries at the regional or national level, which is combined with health insurance data (France) or data collected by active follow-up (Greece). Cases reported in this study were all diagnosed up to the latest dates of complete follow-up, which was between December 2002 and 2005, depending on the study centre. For Germany, Greece, and France, the end of followup was the last known contact, date of diagnosis, or date of death, whichever came first.

\section{Selection of case and control subjects}

Up to December 2006, follow-up has led to the identification of 578 incident cases of non-endocrine pancreas cancer that were coded according to ICD-10 (C25.0-25.3, 25.7-25.9), and for 455 of these cases blood specimens were available. Exclusion criteria were occurrence of other malignant tumours preceding the diagnosis of pancreatic cancer, except for non-melanoma skin cancer. Of the 455 cases, $334(76 \%)$ were microscopically confirmed and the remaining $24 \%$ were diagnosed by imaging results, physical examination, or clinical symptoms. Most tumours occurred in 
the head of the pancreas (42\%), followed by body (7\%) and tail (5\%), while the rest of the tumours were of unknown localisation. For each case, one control subject was selected, that was alive and free of cancer at the time the index case was diagnosed, using an incidence density sampling procedure. All identified cases were matched with one control by centre, sex, age at blood collection ( \pm 3 years), date of blood donation ( \pm 3 months), time of blood donation ( $\pm 2 \mathrm{~h}$ ), fasting status ( $<3 \mathrm{~h}, 3-6 \mathrm{~h},>6 \mathrm{~h}$ after last meal), and use of hormones (oral contraceptive pill, hormone, or oestrogen replacement therapy).

\section{Laboratory assays}

Plasma (in Scandinavian samples) and serum concentrations of CRP were measured by multiplex immunoassays using the Fluorokine MAP Obesity Base Kit (R\&D Systems Inc., Minneapolis, MN, USA). Interleukin- 6 and sTNF receptors were measured by enzyme linked immune sorbent assays using the Quantikine kit (R\&D Systems Inc.). The total amount of free receptor plus the total amount of receptor bound to TNF is measured using this method. All measurements were performed in our specialised immunoassay laboratory of the Division of Cancer Epidemiology (German Cancer Research Center, Heidelberg, Germany). Samples of cases and matched controls were analysed within the same analytical batch. Intra-batch and inter-batch coefficients of variation were 6.6 and $10.8 \%$ for IL-6, 3.6 and $4.1 \%$ for sTNF-R1, 5.5 and $11.0 \%$ for sTNF-R2, and 10.3 and $11.6 \%$ for CRP. Units of IL- 6 are expressed as pg per ml, of sTNF receptors as ng per $\mathrm{ml}$, and of CRP as mg per litre. One batch during the sTNFR2 measurements did not perform well and, therefore, 70 subjects were excluded due to technically invalid results (all from Malmo, Sweden).

\section{Statistical analysis}

Case and control differences across baseline characteristics were assessed by paired $t$-tests (continuous variables) or by generalised McNemar's Test (categorical variables). Spearman's partial rank correlation coefficients $(r)$ adjusted for age, sex, and EPIC recruitment centre were used to assess the strength of associations between waist circumference, waist-hip ratio, BMI, glycated haemoglobin (HbA1c), and inflammatory markers, as well as for the correlation between the inflammatory markers.

Odds ratios (ORs) and corresponding 95\% confidence intervals (CIs) for pancreatic cancer at different serum levels of IL-6, sTNF receptors, and CRP were calculated by conditional logistic regression models, using the exposure assessments of the matched case-control sets. Continuous measurements of the inflammatory markers were $\log 2$ transformed to achieve approximate normality. In this scale, a unit increase corresponds to a doubling of concentration. Quartile cut-points were based on the distribution of biomarkers among controls. Sex-specific quartile cut-points had a negligible effect on risk estimates and were, therefore, not applied. Modelling the median within each quartile as a continuous variable was used to assess linear trends in ORs. Testing the model fit for categorical $v s$ continuous models resulted in very similar AICs, with a slightly better fit for the latter model.

Inflammatory markers may be downstream in the causal chain of excess body weight, smoking, or diabetes and pancreatic cancer. Alternatively, other pathways might explain associations of these conditions with risk of pancreatic cancer and, hence, inflammatory markers may be independently related to cancer or not at all. We tried to elucidate these rather complex and yet unknown relationships in our study by applying different adjustment models and by performing several subgroups analyses. All these models and methods are of exploratory nature in our study.

Potential confounding of factors other than those controlled for by matching were examined by assessing the association of these factors with pancreatic cancer risk using unconditional logistic regression models adjusted for matching factors, by correlation analyses, and by including these as additional factors in conditional logistic regression models. Body mass index, waist-hip ratio, waist circumference, alcohol consumption, current and past tobacco smoking, and diabetes were considered as potential confounders. Variables remained in the models if they were associated with pancreatic cancer, correlated with the inflammatory markers, or changed the $\beta$-estimate by more than $10 \%$. On the basis of these conditions, BMI as a continuous variable and smoking as a categorical variable (never smoking, former smoking (quitting smoking $<10$ years ago, $\geqslant 10$ years ago), current smoking $(<10,10-20, \geqslant 20$ cigarettes a day), missing) were considered as confounding factors and remained in the multivariate adjusted model. To assess a possible confounding effect of diabetes on the risk associations, we controlled for diabetes in further exploratory analyses. Subjects were defined as diabetics if they self-reported the condition in the baseline questionnaire at recruitment $(n=52)$ and/or had HbAlc levels $\geqslant 6.5 \%$ in the current study $(n=93)$. This percentage is used as a cut-off for diabetes diagnosis (ADA, 2009). Glycated haemoglobin has been measured previously in the same study population (Grote et al, 2011). Physical activity and socioeconomic status did not markedly change the risk estimates and were, therefore, not included in the final model.

Subgroup analyses were performed to assess possible effect modifications by sex, diabetes and smoking status, by median age (62 years), waist circumference ( $96 \mathrm{~cm}$ for men, 80 for women), waist-hip ratio (0.95 for men, 0.80 for women), and median BMI $\left(26.2 \mathrm{~kg} \mathrm{~m}^{-2}\right.$ for men, 24.6 for women), or by lag-time (time between blood collection and diagnosis of pancreatic cancer, $\leqslant v s>5$ years). Cross-product terms were added in logistic regression models and Wald tests were performed to examine whether any apparent heterogeneity of effect was significant. To limit reverse causation bias, which could occur when the advanced tumour causes changes in inflammatory marker levels, we performed subgroup analyses with 2 years of follow-up as a cut-point $(\leqslant v s>2$ years $)$.

All statistical analyses were conducted using the Statistical Analysis System (SAS) software package, Version 9.2 (SAS Institute Inc., Cary, NC, USA). All statistical tests were twotailed and significant at the $5 \%$ level.

\section{RESULTS}

Baseline characteristics of pancreatic cancer cases and matched control subjects are shown in Table 1 . Mean age at recruitment into the initial cohort was 58 years and mean age of cases at pancreatic cancer diagnosis was 63 years, resulting in mean followup time of 5.3 years for cases (range 0-13). Female pancreatic cancer cases had a significantly higher BMI and waist circumference than corresponding controls, but no difference in waist-hip ratio was observed. For men, however, no significant difference for any of the anthropometric measures comparing cases and controls was seen. A higher percentage of cases currently smoked compared with controls ( $31 \%$ vs $22 \%)$. At baseline, cases also reported more often to be diabetic and/or had HbAlc levels $\geqslant 6.5 \%$ compared with controls ( $14 \%$ vs $8 \%$ ). However, these results are not mutually adjusted and serve descriptive purposes only.

Among controls, sTNF-R1 and sTNF-R2 showed a high degree of correlation. The correlation of circulating CRP levels with IL-6, sTNF-R1, and sTNF-R2 concentrations was relatively high with Spearman's rank correlation coefficients up to 0.44. Waist circumference, BMI, and waist-hip ratio correlated moderately with CRP and IL-6, and to lesser extent with sTNF-R1 but not with sTNF-R2 concentrations (Table 2). Participants with diabetes (self-reported at baseline and/or $\mathrm{HbAlc} \geqslant 6.5 \%$ ) and those who 
Table

Baseline characteristics of pancreatic cancer cases and matched controls

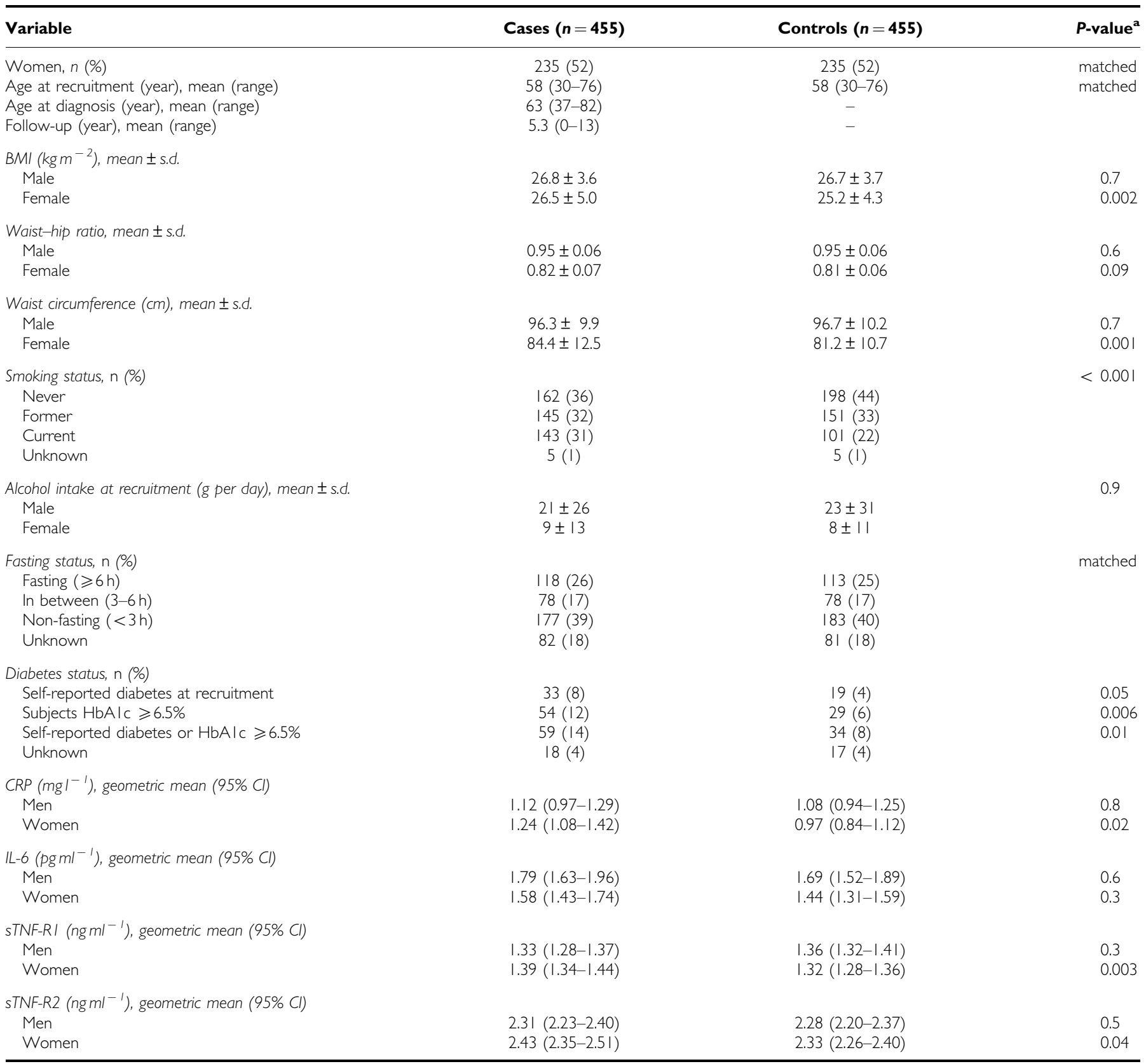

Abbreviations: $\mathrm{Cl}=$ confidence interval; s.d. = standard deviation. Note: matching factors were EPIC recruitment centre, sex, age at blood collection, date of blood donation, time of blood donation, fasting status, and use of hormones (in women). ${ }^{2} P$-values for continuous variables were based on paired $t$-tests; $P$-values for categorical variables were based on generalised McNemar's tests.

smoked had higher levels of CRP and IL-6 than non-diabetics (Table 2). Mutual adjustments for smoking categories and/or BMI resulted in unaltered (diabetes) or stronger associations (smoking, data not shown).

The potential confounders or effect modifiers overweight $(\mathrm{OR}=1.05$ (95\% CI 1.01-1.08), per 5 BMI units), smoking $(\mathrm{OR}=1.84$ (95\% CI 1.30-2.60), current vs never), and diabetes $(\mathrm{OR}=1.74(95 \%$ CI $1.12-2.71))$ were associated with risk of pancreatic cancer in our study.

Pancreatic cancer risk tended to be increased with higher levels of sTNF-R2 (crude OR $=1.52$ (95\% CI 0.97-2.39) comparing highest with lowest quartiles, $P$-trend over quartiles $=0.07$ ), but these associations were not significant at the 5\% level, and BMI and smoking adjustments attenuated the risks of pancreatic cancer
(Table 3). Elevated CRP (crude OR $=1.36$ (95\% CI 0.92-2.01), $P$-trend $=0.26), \quad$ IL-6 $\quad(\mathrm{OR}=1.30 \quad(95 \% \quad$ CI $\quad 0.84-2.00)$, $P$-trend $=0.61)$, and sTNF-R1 levels $\quad(\mathrm{OR}=1.23 \quad(95 \% \quad \mathrm{CI}$ $0.78-1.94), P$-trend $=0.23$ ) showed no significant association with risk of pancreatic cancer. Adjustments for HbAlc levels and mutually for the other inflammatory markers in addition to BMI and smoking categories attenuated risk estimates for elevated levels of inflammatory markers closer to 1.0 (data not shown). Exclusion of subjects with CRP levels above $10 \mathrm{mgl}^{-1}$ (as this is more likely an indication for an acute rather than a chronic inflammatory state) had no effect on the association between CRP levels and pancreatic cancer risk (data not shown). Women tended to be at increased pancreatic cancer risks for higher CRP or sTNF receptor levels, and specifically so for sTNF-R1, although risk 
Table 2 Correlation $\left(95 \% \mathrm{Cl}\right.$ ) between inflammatory markers and selected covariates in control participants ${ }^{\mathrm{a}}$

\begin{tabular}{|c|c|c|c|c|}
\hline IL-6 & $0.44(0.35-0.53)$ & & & \\
\hline sTNF-RI & $0.29(0.18-0.39)$ & $0.33(0.22-0.42)$ & & \\
\hline BMI & $0.40(0.30-0.49)$ & $0.29(0.18-0.39)$ & $0.17(0.06-0.28)$ & $0.05(-0.06$ to 0.16$)$ \\
\hline Waist & $0.32(0.22-0.42)$ & $0.31(0.20-0.41)$ & $0.21(0.10-0.31)$ & $0.10(-0.01$ to 0.21$)$ \\
\hline WHR & $0.23(0.13-0.34)$ & $0.25(0.14-0.35)$ & $0.16(0.04-0.26)$ & $0.09(-0.03$ to 0.20$)$ \\
\hline $\mathrm{HbAlc}$ & $0.16(0.05-0.27)$ & $0.09(-0.02$ to 0.20$)$ & $0.10(-0.01$ to 0.21$)$ & $0.01(-0.10$ to 0.12$)$ \\
\hline Sex ${ }^{d}$ & $1.07(0.95-1.21)$ & $1.21(1.02-1.44)$ & $1.79(0.97-3.31)$ & $0.90(0.50-1.62)$ \\
\hline $\mathrm{Age}^{\mathrm{e}}$ & $0.13(0.03-0.23)$ & $0.18(0.08-0.28)$ & $0.30(0.20-0.39)$ & $0.32(0.22-0.4 I)$ \\
\hline
\end{tabular}

Abbreviations: CRP = C-reactive protein; IL-6 = interleukin-6; sTNF-RI and sTNF-R2 = soluble tumour necrosis factor receptors I and 2; BMI = body mass index; waist = waist

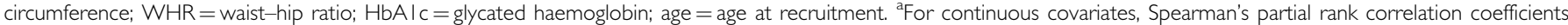
were applied. For categorical covariates we used logistic regression. Both methods were performed in controls and adjusted for age, sex, and EPIC recruitment centre if not stated otherwise. ${ }^{b}$ Diabetic ( $\mathrm{HbAlc} \geqslant 6.5 \%$ or self-reported diabetes at baseline) vs non-diabetic participants. ${ }^{\mathrm{C}} \mathrm{Current}$ vs never smokers. ${ }^{\mathrm{d}}$ Men vs women, adjusted for age and EPIC recruitment centre. ${ }^{e}$ Adjusted for sex and EPIC recruitment centre.

Table 3 Risk $(\mathrm{OR}(95 \% \mathrm{Cl}))$ of pancreatic cancer by quartiles of CRP, IL-6, and sTNF receptors, all subjects combined and stratified by sex

\begin{tabular}{|c|c|c|c|c|c|c|c|}
\hline & & \multicolumn{4}{|c|}{ Quartiles $^{\text {b }}$} & \multirow[b]{2}{*}{ P-trend ${ }^{c}$} & \multirow[b]{2}{*}{$\begin{array}{l}\text { OR for doubling in } \\
\text { concentration }\end{array}$} \\
\hline & & I & 2 & 3 & 4 & & \\
\hline CRP & $\begin{array}{l}\text { Quartile cut-offs (mgl- }{ }^{-1} \text { ) } \\
\text { No. of cases/controls (total 449/449) } \\
\text { Crude } \\
\text { Adjusted for smoking, BMI } \\
\text { Men, crude } \\
\text { Adjusted for smoking, BMI } \\
\text { Women, crude } \\
\text { Adjusted for smoking, BMI }\end{array}$ & $\begin{array}{l}0.02-0.51 \\
88 / 112 \\
1.0 \\
1.0 \\
1.0 \\
1.0 \\
1.0 \\
1.0\end{array}$ & $\begin{array}{c}0.52-1.04 \\
112 / 112 \\
1.30(0.88-1.94) \\
1.25(0.83-1.88) \\
1.38(0.76-2.52) \\
1.39(0.75-2.58) \\
1.15(0.67-1.97) \\
1.19(0.67-2.11)\end{array}$ & $\begin{array}{c}1.05-2.05 \\
130 / 1 \mid 3 \\
1.45(1.00-2.10) \\
1.20(0.80-1.79) \\
0.98(0.56-1.70) \\
0.93(0.52-1.66) \\
2.14(1.27-3.59) \\
1.65(0.92-2.98)\end{array}$ & $\begin{array}{c}2.06-34.07 \\
119 / 112 \\
1.36(0.92-2.01) \\
1.02(0.66-1.57) \\
1.23(0.68-2.21) \\
1.09(0.58-2.04) \\
1.44(0.85-2.47) \\
0.99(0.54-1.81)\end{array}$ & $\begin{array}{l}0.3 \\
0.6 \\
0.9 \\
0.7 \\
0.1 \\
0.6\end{array}$ & $\begin{array}{l}1.08(0.99-1.18) \\
1.01(0.92-1.11) \\
1.02(0.90-1.15) \\
1.00(0.88-1.13) \\
1.16(1.02-1.31) \\
1.02(0.89-1.18)\end{array}$ \\
\hline IL-6 & $\begin{array}{l}\text { Quartile cut-offs ( } \mathrm{pg} \mathrm{ml}^{-1} \text { ) } \\
\text { No. of cases/controls (total 424/424) } \\
\text { Crude }^{\mathrm{d}} \\
\text { Adjusted for smoking, BMI } \\
\text { Men, crude } \\
\text { Adjusted for smoking, BMI } \\
\text { Women, crude } \\
\text { Adjusted for smoking, BMI }\end{array}$ & $\begin{array}{l}0.16-0.94 \\
86 / 106 \\
1.0 \\
1.0 \\
1.0 \\
1.0 \\
1.0 \\
1.0\end{array}$ & $\begin{array}{c}0.95-1.57 \\
123 / 106 \\
1.45(0.98-2.15) \\
1.29(0.86-1.94) \\
2.02(1.11-3.68) \\
1.88(1.00-3.51) \\
1.10(0.65-1.87) \\
0.92(0.52-1.62)\end{array}$ & $\begin{array}{c}1.58-2.65 \\
\mid 08 / 107 \\
1.28(0.85-1.93) \\
0.97(0.62-1.51) \\
1.73(0.92-3.26) \\
1.51(0.75-3.04) \\
1.01(0.58-1.75) \\
0.71(0.38-1.33)\end{array}$ & $\begin{array}{c}2.66-9.66 \\
107 / 105 \\
1.30(0.84-2.00) \\
1.01(0.64-1.61) \\
1.36(0.70-2.64) \\
1.21(0.60-2.45) \\
1.29(0.72-2.33) \\
0.83(0.43-1.60)\end{array}$ & $\begin{array}{l}0.6 \\
0.7 \\
0.9 \\
0.6 \\
0.4 \\
0.7\end{array}$ & $\begin{array}{l}1.09(0.95-1.26) \\
0.99(0.85-1.16) \\
1.07(0.86-1.32) \\
1.00(0.80-1.25) \\
1.12(0.92-1.36) \\
0.96(0.77-1.19)\end{array}$ \\
\hline sTNF-RI & $\begin{array}{l}\text { Quartile cut-offs (ng ml }{ }^{-1} \text { ) } \\
\text { No. of cases/controls (total 390/390) } \\
\text { Crude }^{\text {d }} \\
\text { Adjusted for smoking, BMI } \\
\text { Men, crude } \\
\text { Adjusted for smoking, BMI } \\
\text { Women, crude } \\
\text { Adjusted for smoking, BMI }\end{array}$ & $\begin{array}{l}0.75-1.13 \\
86 / 97 \\
1.0 \\
1.0 \\
1.0 \\
1.0 \\
1.0 \\
1.0\end{array}$ & $\begin{array}{l}|.| 4-|.3| \\
84 / 98 \\
0.97(0.63-1.49) \\
0.84(0.54-1.32) \\
0.72(0.39-1.33) \\
0.7 \mid(0.38-1.35) \\
1.23(0.67-2.28) \\
1.03(0.53-1.99)\end{array}$ & $\begin{array}{c}1.32-1.58 \\
120 / 98 \\
1.41(0.94-2.12) \\
1.18(0.77-1.82) \\
0.81(0.44-1.49) \\
0.79(0.42-1.49) \\
2.25(1.26-4.00) \\
1.75(0.93-3.27)\end{array}$ & $\begin{array}{c}1.59-2.95 \\
100 / 97 \\
1.23(0.78-1.94) \\
0.95(0.58-1.55) \\
0.71(0.36-1.39) \\
0.64(0.31-1.29) \\
1.97(1.02-3.79) \\
1.47(0.72-3.02)\end{array}$ & $\begin{array}{l}0.2 \\
0.9 \\
0.4 \\
0.3 \\
0.02 \\
0.2\end{array}$ & $\begin{array}{l}1.39(0.87-2.23) \\
1.10(0.66-1.81) \\
0.67(0.34-1.35) \\
0.63(0.30-1.32) \\
2.74(1.37-5.47) \\
2.05(0.97-4.34)\end{array}$ \\
\hline sTNF-R2 & $\begin{array}{l}\text { Quartile cut-offs (ng ml }{ }^{-1} \text { ) } \\
\text { No. of cases/controls (total 4|4/4|4) } \\
\text { Crude }^{\mathrm{d}} \\
\text { Adjusted for smoking, BMI } \\
\text { Men, crude } \\
\text { Adjusted for smoking, BMI } \\
\text { Women, crude } \\
\text { Adjusted for smoking, BMI }\end{array}$ & $\begin{array}{l}0.83-1.95 \\
90 / 103 \\
1.0 \\
1.0 \\
1.0 \\
1.0 \\
1.0 \\
1.0\end{array}$ & $\begin{array}{c}1.96-2.31 \\
102 / 104 \\
1.17(0.77-1.77) \\
1.15(0.74-1.77) \\
1.06(0.59-1.92) \\
1.02(0.55-1.88) \\
1.28(0.71-2.29) \\
1.22(0.65-2.28)\end{array}$ & $\begin{array}{c}2.32-2.68 \\
99 / 104 \\
1.18(0.75-1.85) \\
1.08(0.68-1.72) \\
0.98(0.51-1.90) \\
0.92(0.46-1.81) \\
1.40(0.76-2.60) \\
1.17(0.60-2.28)\end{array}$ & $\begin{array}{c}2.69-4.82 \\
123 / 103 \\
1.52(0.97-2.39) \\
1.42(0.89-2.27) \\
1.20(0.63-2.29) \\
1.27(0.65-2.46) \\
1.92(1.00-3.67) \\
1.72(0.86-3.44)\end{array}$ & $\begin{array}{l}0.07 \\
0.2 \\
0.6 \\
0.4 \\
0.05 \\
0.1\end{array}$ & $\begin{array}{l}1.55(0.99-2.44) \\
1.40(0.88-2.23) \\
1.24(0.66-2.33) \\
1.35(0.69-2.61) \\
1.95(1.03-3.69) \\
1.60(0.80-3.17)\end{array}$ \\
\hline
\end{tabular}

Abbreviations: $\mathrm{Cl}=$ confidence interval; No. = number; CRP, IL-6, and sTNF receptor concentrations on continuous scales were log2 transformed. Smaller number of subjects due to missing laboratory values. ${ }^{\mathrm{a} C}$ rude $P$-interaction over quartiles, for CRP $=0.03, \mathrm{IL}-6=0.2$, sTNF-RI $=0.09$, sTNF-R2 $=0.8$. Body mass index and smoking-adjusted $P$-interaction, for $C R P=0.03, I L-6=0.2$, sTNF-RI $=0.1$, sTNF-R2 $=0.9$. ${ }^{b} Q$ uartile cut-points were based on the distribution of controls. ${ }^{C} P$-trend test was based on median values of each quartile. 'Logistic regression conditioned on matching factors (EPIC recruitment centre, sex, age at recruitment, date at entry in the cohort, time between blood sampling and last consumption of foods and drinks, hormone use). Adjusting variables in further model: smoking (former smokers adjusted for quitting smoking ( $<10$ or $\geqslant 10$ years ago), current smokers adjusted for number of cigarettes $(1-9,10-19$, or $\geqslant 20)$ ), and BMl (continuous, $\left(\mathrm{kgm}^{-1}\right)$ ).

estimates were inconsistently significant between categorical and continuous analyses and between crude and BMI and smokingadjusted models (Table 3 ).

Tests for heterogeneity of continuous sTNF receptors, adjusted for matching factors, resulted in statistically significant differences in pancreatic cancer risk by median BMI, diabetes, and smoking status, but not by median waist circumference, waist-hip ratio or median age. Compared with never smokers, risks in former and current smokers were elevated, albeit not statistical significant. Diabetics $(P$-interaction $=0.001)$ and subjects with a BMI above the median $(P$-interaction $=0.04)$ had a significantly higher risk of pancreatic cancer with elevated levels of sTNF-R2 than 
A

\begin{tabular}{|c|c|c|c|}
\hline & STN & & \\
\hline Subgroup & $\mathrm{Ca} / \mathrm{Co}$ & OR $(95 \% \mathrm{Cl})$ & P-int ${ }^{a}$ \\
\hline All & $390 / 390$ & $1.39(0.87-2.23)$ & \\
\hline $\mathrm{BMI}$ median $^{\mathrm{b}}$ & $191 / 209$ & $1.14(0.60-2.18)$ & 0.3 \\
\hline $\mathrm{BMI} \geqslant$ median & $236 / 203$ & $1.19(0.68-2.08)$ & \\
\hline Non-diabetics & $354 / 366$ & $1.08(0.68-1.70)$ & 0.003 \\
\hline Diabetics $^{c}$ & $56 / 30$ & $3.09(0.84-11.36)$ & \\
\hline Never smoker & $155 / 184$ & $1.07(0.55-2.11)$ & 0.05 \\
\hline Former smoker & $133 / 131$ & $1.10(0.52-2.34)$ & \\
\hline Current smoker & $134 / 92$ & $1.20(0.54-2.68)$ & \\
\hline FUP $\leqslant 2$ years $^{d}$ & $73 / 69$ & $0.81(0.26-2.55)$ & 0.3 \\
\hline FUP $>2$ years & $354 / 343$ & $1.55(0.92-2.62)$ & \\
\hline
\end{tabular}

\section{B}

\begin{tabular}{|c|c|c|c|}
\hline & & & \\
\hline Subgroup & $\mathrm{Ca} / \mathrm{Co}$ & OR $(95 \% \mathrm{Cl})$ & P-int ${ }^{a}$ \\
\hline All & $414 / 414$ & $1.55(0.99-2.44)$ & \\
\hline 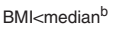 & $179 / 204$ & $0.89(0.50-1.58)$ & 0.04 \\
\hline $\mathrm{BMI} \geqslant$ median & $238 / 213$ & $1.93(1.11-3.37)$ & \\
\hline Non-diabetics & $349 / 375$ & $1.12(0.73-1.72)$ & 0.001 \\
\hline Diabetics $^{c}$ & $54 / 29$ & $4.76(1.11-20.37)$ & \\
\hline Never smoker & $148 / 187$ & $0.92(0.47-1.81)$ & 0.001 \\
\hline Former smoker & $133 / 136$ & $1.40(0.69-2.84)$ & \\
\hline Current smoker & $131 / 89$ & $1.61(0.77-3.37)$ & \\
\hline $\mathrm{FUP} \leqslant 2$ years $^{\mathrm{d}}$ & $73 / 73$ & $0.97(0.34-2.80)$ & 0.3 \\
\hline FUP $>2$ years & $344 / 344$ & $1.72(1.05-2.84)$ & \\
\hline
\end{tabular}

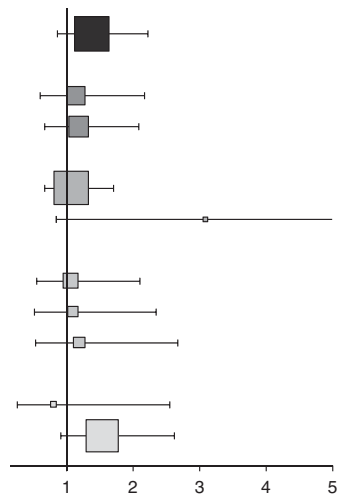

C

\begin{tabular}{|c|c|c|c|}
\hline & & & \\
\hline Subgroup & $\mathrm{Ca} / \mathrm{Co}$ & OR $(95 \% \mathrm{Cl})$ & $P$-int ${ }^{a}$ \\
\hline All & $449 / 449$ & $1.08(0.99-1.18)$ & \\
\hline BMI<median $^{\text {b }}$ & $200 / 226$ & $1.13(1.00-1.28)$ & 0.3 \\
\hline $\mathrm{BMI} \geqslant$ median & $250 / 226$ & $1.01(0.89-1.15)$ & \\
\hline Non-diabetics & $373 / 401$ & $1.05(0.95-1.15)$ & 0.1 \\
\hline Diabetics $^{\mathrm{C}}$ & $59 / 34$ & $1.17(0.85-1.63)$ & \\
\hline Never smoker & $161 / 197$ & $1.08(0.94-1.23)$ & 0.9 \\
\hline Former smoker & $143 / 149$ & $1.09(0.93-1.29)$ & \\
\hline Current smoker & $141 / 101$ & $1.04(0.88-1.23)$ & \\
\hline FUP $\leqslant 2$ years $^{d}$ & 77/77 & $1.10(0.90-1.35)$ & 0.9 \\
\hline FUP $>2$ years & $373 / 375$ & $1.08(0.98-1.18)$ & \\
\hline
\end{tabular}
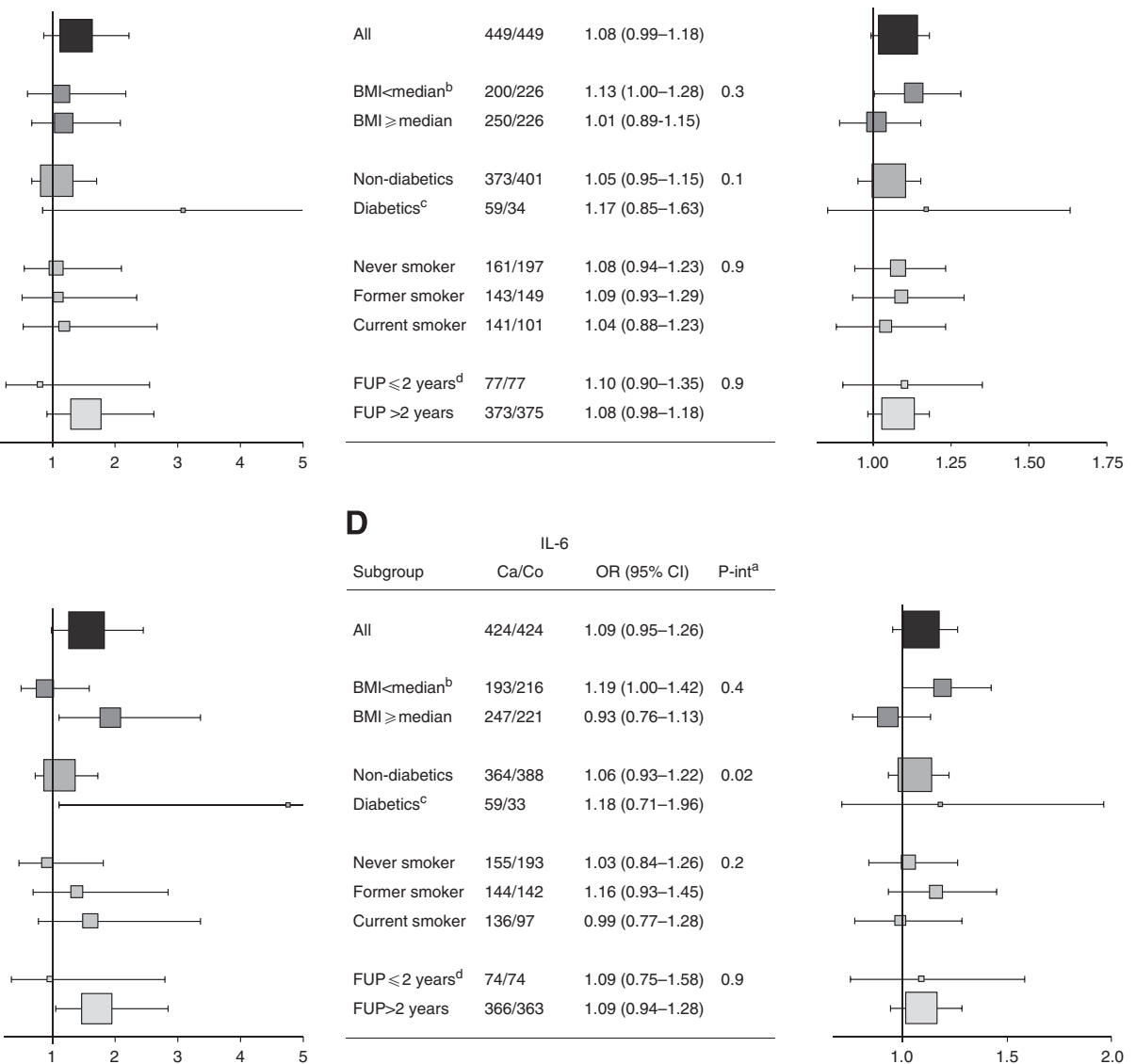

D

\begin{tabular}{|c|c|c|c|}
\hline \multirow[b]{2}{*}{ Subgroup } & \multicolumn{2}{|c|}{ IL-6 } & \multirow[b]{2}{*}{ P-int ${ }^{2}$} \\
\hline & $\mathrm{Ca} / \mathrm{Co}$ & OR $(95 \% \mathrm{Cl})$ & \\
\hline All & $424 / 424$ & $1.09(0.95-1.26)$ & \\
\hline BMI<median ${ }^{\text {b }}$ & $193 / 216$ & $1.19(1.00-1.42)$ & 0.4 \\
\hline $\mathrm{BMI} \geqslant$ median & $247 / 221$ & $0.93(0.76-1.13)$ & \\
\hline Non-diabetics & $364 / 388$ & $1.06(0.93-1.22)$ & 0.02 \\
\hline Diabetics $^{c}$ & $59 / 33$ & $1.18(0.71-1.96)$ & \\
\hline Never smoker & $155 / 193$ & $1.03(0.84-1.26)$ & 0.2 \\
\hline Former smoker & $144 / 142$ & $1.16(0.93-1.45)$ & \\
\hline Current smoker & $136 / 97$ & $0.99(0.77-1.28)$ & \\
\hline FUP $\leqslant 2$ years $^{d}$ & $74 / 74$ & $1.09(0.75-1.58)$ & 0.9 \\
\hline FUP $>2$ years & $366 / 363$ & $1.09(0.94-1.28)$ & \\
\hline
\end{tabular}

Figure I Crude relative risks (OR $(95 \% \mathrm{Cl})$ ) of pancreatic cancer for a doubling in sTNF receptor concentrations $(\mathbf{A}$ and $\mathbf{B})$, CRP $(\mathbf{C})$, and IL-6 (D), all and stratified by median BMI (26.2 for men, 24.6 for women), diabetes, smoking status, and length of follow-up ( $\leqslant 2$ vs $>2$ years). Note: Stratified analysis using unconditional logistic regression was adjusted for matching factors (EPIC recruitment centre, sex, age at blood collection, date of blood donation, time of blood donation, fasting status, and use of hormones). $\mathrm{Ca} / \mathrm{Co}=$ number of cases/controls. Size of squares is proportional to number of participants in the respective subgroup; squares represent ORs, with error bars indicating $95 \% \mathrm{Cls} .{ }^{\text {a }} \mathrm{P}$ for interaction was based on the Wald statistics, adjusted for matching factors. 'Median BMI for male controls was $26.20 \mathrm{~kg} \mathrm{~m}^{-2}$, for female controls $24.61 \mathrm{~kg} \mathrm{~m}^{-2}$. 'Diabetics included subjects with self-reported diabetes status at baseline and subjects with glycated haemoglobin ( $\mathrm{HbAlc}$ ) levels $\geqslant 6.5 \%$ or both. ${ }^{\mathrm{d}} \mathrm{FUP}=$ follow-up time (years), using conditional logistic regression.

non-diabetics or subjects with lower than median BMI, respectively (Figure 1B). Adjusting subgroup analyses for BMI, smoking categories, HbAlc levels, and/or mutually for inflammatory markers attenuated the risk estimates to non-significance (data not shown). Interestingly, higher circulating CRP and IL-6 levels tended to be related to increased pancreatic cancer risk in leaner subjects, although ORs and tests for interaction were not statistically significant (Figure $1 \mathrm{C}$ and D).

\section{DISCUSSION}

In our nested case-control study of 455 pancreatic cancer subjects and 455 individually matched controls, higher circulating levels of sTNF-R2, but not of sTNF-R1, CRP, and IL-6 levels, tended to be positively associated with the risk of pancreatic cancer. Stratification by sex revealed significantly increased pancreatic cancer risks in women for higher sTNF-R1 levels. Positive associations between sTNF-R2 and pancreatic cancer seemed to be likely for diabetic subjects, those with a higher BMI, and possibly also for smokers.

In the acute-phase response to tissues damage, infection, inflammation, or malignant neoplasia, CRP is increasingly produced by hepatocytes, predominantly under control by IL-6. C-reactive protein binds to damaged cell membranes or apoptotic cells, forming an aggregate that activates the complement pathway, resulting in the phagocytosis of the damaged cells and in increased proinflammatory pathophysiological effects. C-reactive protein, therefore, reflects ongoing inflammation and/or tissue damage and functions as a proinflammatory mediator. In this context, it may not only be a marker of a disease, but it may also contribute to pathogenesis (Pepys and Hirschfield, 2003). In several small hospital-based case-control studies, CRP levels were significantly higher in pancreatic cancer cases compared with chronic pancreatitis patients or controls (Barber et al, 1999; Moses et al, 2009; Mroczko et al, 2010). In addition, elevated levels of CRP were associated with a poor prognosis in pancreatic cancer patients (McKay et al, 2008). Prospectively, no association was observed in a Greek study with 14 pancreatic cancer cases (Trichopoulos et al, 2006), whereas a weak decrease in pancreatic cancer risk with an OR of 0.94 (95\% CI 0.89-0.99) was seen among 311 cases in the Alpha-Tocopherol, Beta-Carotene Cancer Prevention Study (ATBC) cohort of male Finish smokers (Douglas et al, 2010). The same authors did not find an association in the Ovarian Cancer Screening Trial (PLCO) or in combined analyses of 
both cohorts. Our results are in line with the prospective Greek and PLCO study showing no association of CRP with risk of pancreatic cancer.

No prospective study has been conducted so far to assess the association of circulating TNF- $\alpha$, its soluble receptors, or IL-6 levels with risk of pancreatic cancer, both upregulators of CRP. Tumour necrosis factor- $\alpha$ is a proinflammatory cytokine produced by many cell types, including cancer cells, upon exogenous noxious stimuli. The effects of TNF- $\alpha$ are mediated mainly by two receptors, TNF-R1 and TNF-R2, which also circulate in soluble forms upon shedding. Tumour necrosis factor receptor activation leads to induction of genes involved in inflammation and cell survival, resulting in the activation of nuclear factor- $\kappa \mathrm{B}(\mathrm{NF}-\kappa \mathrm{B})$. However, if NF- $\kappa \mathrm{B}$ activation is inadequate, apoptosis is mediated via accumulation of reactive oxygen species as a late response to TNF- $\alpha$. This cytokine, thus, is not only involved in maintenance of the immune system, but also in pathological processes such as malignant diseases. The majority of cell types and tissues express both receptor types (Balkwill, 2006), and among colon cancer patients it has been shown that the concentrations of sTNF-Rs correlate with the stage of disease as tumour cells have a greater tendency than non-malignant cells to shed forms of their cell surface proteins (Aderka, 1996). Soluble TNF receptors can serve as TNF antagonists, carrier proteins of TNF, slow release reservoirs for TNF, and stabilisers of TNF bioactivity. It is not known, however, whether the two soluble receptors have distinct or similar functions (Aderka, 1996), and based on this, we cannot explain why we observed a potential increase in pancreatic cancer risk for elevated sTNF-R2 but not for sTNF-R1. It might be, however, that sTNF-R2 has a more prominent role in pancreatic cancer development. This aspect needs to be explored in functional studies. So far, TNF- $\alpha$ and/or the soluble receptors have been assessed in hospital-based case-control studies with pancreatic cancer patients, observing either higher levels of TNF- $\alpha /$ soluble TNF receptors among pancreatic cancer subjects than among controls (healthy volunteers or chronic pancreatitis patients (Barber et al, 1999; Talar-Wojnarowska et al, 2009)), or no difference in serum levels (Ebrahimi et al, 2004). To our knowledge, our nested case-control study within the prospective EPIC cohort study is the first to address the association of sTNF receptors with risk of pancreatic cancer, and we observed a nonsignificant increase in risk overall, which was more apparent for sTNF-R2 than sTNF-R1, and which was attenuated after adjustments for smoking status, BMI, and HbAlc levels or diabetes status. It is unclear why we found a difference in risk between men and women with elevated risks for increasing levels of sTNF-R1 in women only.

As with TNF- $\alpha$, pancreatic cancer patients' IL- 6 concentrations have shown to be higher than in healthy controls in hospital-based case-control studies (Barber et al, 1999; Ebrahimi et al, 2004; Moses et al, 2009; Mroczko et al, 2010). In contrast to these observations, in our prospective study we did not find elevated pre-diagnostic IL-6 concentrations in subjects who became pancreatic cancer cases later in time compared to non-cancer controls at baseline. Interleukin- 6 is synthesised by many cell types in response to stimulation from TNF- $\alpha$ and IL-1, and indirectly regulates cell proliferation and apoptosis through its activation of other factors. Therefore, IL-6 has a role in chronic inflammation, which may enhance cancer development (Hodge et al, 2005). However, due to the small number of prospective studies so far investigating the relationship of IL-6 with cancer, a recent published review concluded that it is yet impossible to determine whether IL-6 is causally related to cancer (Heikkilä et al, 2008).

It has been shown in a wide range of studies that CRP, IL-6, TNF- $\alpha$, and TNF receptor levels vary by body weight, with higher levels among overweight or obese compared with normal weight subjects, and with decreasing levels during weight loss (Himmerich et al, 2006; Forsythe et al, 2008). Furthermore, compared with never smokers, cigarette smokers also have significantly higher levels of CRP and IL-6, and possibly also of TNF receptors (Fernandez-Real et al, 2003). Finally, subclinical systemic inflammation has been reported in type 2 diabetes (Kolb and MandrupPoulsen, 2005), including elevated levels of the aforementioned and evaluated parameters in our study. In our study, elevated levels of CRP, IL-6 and sTNF-R1 correlated with excess weight and, in addition, higher CRP and IL-6 levels were associated with smoking and diabetes.

Furthermore, overweight, smoking, or diabetic participants at baseline were at increased pancreatic cancer risk. This risk was even stronger if overweight or diabetic participants had elevated levels of sTNF-R2, even though this marker was not correlated with BMI or associated with diabetes in controls. This can be interpreted as sTNF-R2 being a mediator of the relationship between overweight and/or diabetes and pancreatic cancer. A similar scenario is likely for sTNF-R1, but our results do not clearly support this hypothesis (Figure 1A). In contrast, stratification by median BMI, diabetes, or smoking status resulted in similar weak risk estimates for elevated CRP and IL-6 concentrations. It seems as if, regardless of the presence of a putative pancreatic cancer risk factor (overweight, diabetes, and smoking), these inflammatory markers are not associated with pancreatic cancer risk themselves. In addition, they also do not appear to be in the causal chain between risk factor and cancer.

Some strengths and limitations of our study should be mentioned. Although a single measurement of a biomarker, as assessed in our study, could result in random misclassification, CRP, IL-6, and sTNF receptors have been shown to be reliably measured over time (Gu et al, 2009; Clendenen et al, 2010). A major strength of our study is that questionnaire data and blood samples were collected prospectively around the same time point, prior to pancreatic cancer diagnosis, which reduces the possibility of reverse causation bias to some extent. In addition, pancreatic cancer risk seemed to be stronger for elevated sTNF receptor levels among subjects with longer follow-up times. A limitation of our study is that information on pancreatic or liver disorders, on inflammatory diseases, or on use of anti-inflammatory drugs was not recorded for most of the EPIC centres; therefore, controlling for these potential confounders was not possible. Consequently, we cannot exclude the possibility that the observed suggestive increased pancreatic cancer risk among individuals with elevated sTNF-R2 levels may partly be due to chronic pancreatitis or impaired liver function, for example. Furthermore, number of subjects in specific subgroups were rather small; thus, we cannot rule out that results obtained from these analyses are chance findings. Further large prospective studies are needed to verify our results in the respective subgroups with sufficient power to detect significant risk associations.

\section{CONCLUSION}

Prospectively, CRP and IL-6 do not seem to play a role in our study with respect to risk of pancreatic cancer, whereas sTNF-R1 seemed to be a risk factor in women and sTNF-R2 might be a mediator in the risk relationship between overweight and diabetes with pancreatic cancer. In order to clarify the role of proinflammatory proteins and cytokines in the pathogenesis of exocrine pancreatic cancer, more prospective studies in large settings are needed, controlling for the potential bias of other conditions and stratifying by sex.

\section{ACKNOWLEDGEMENTS}

We thank Laure Dossus for greatly appreciated statistical support, and Britta Lederer and Sigrid Henke for their excellent work in performing the immunoassays. We would also like to take the 
opportunity to thank the anonymous referees for greatly improving our manuscript. VAG was funded by a grant from the German Research Foundation, Graduiertenkolleg 793: Epidemiology of communicable and chronic non-communicable diseases and their interrelationships. This work was supported by WCRF UK and WCRF International, grant no. 2009/39. The coordination of EPIC is financially supported by the European Commission (DG-SANCO) and the International Agency for Research on Cancer. The national cohorts are supported by Danish Cancer Society (Denmark); Ligue Contre le Cancer, Institut Gustave Roussy, Mutuelle Générale de l'Education Nationale, Institut National de la Santé et de la Recherche Médicale (INSERM) (France); Deutsche Krebshilfe, Deutsches Krebsforschungszentrum (DKFZ) and Federal Ministry of Education and Research (Germany); Ministry of Health and Social Solidarity, Stavros Niarchos Foundation and Hellenic Health Foundation (Greece);

\section{REFERENCES}

ADA (2009) International Expert Committee report on the role of the A1C assay in the diagnosis of diabetes. Diabetes Care 32(7): 1327-1334

Aderka D (1996) The potential biological and clinical significance of the soluble tumor necrosis factor receptors. Cytokine Growth Factor Rev 7(3): 231-240

Balkwill F (2006) TNF-alpha in promotion and progression of cancer. Cancer Metastasis Rev 25(3): 409-416

Barber MD, Fearon KC, Ross JA (1999) Relationship of serum levels of interleukin-6, soluble interleukin-6 receptor and tumour necrosis factor receptors to the acute-phase protein response in advanced pancreatic cancer. Clin Sci (Lond) 96(1): 83-87

Clendenen TV, Arslan AA, Lokshin AE, Idahl A, Hallmans G, Koenig KL, Marrangoni AM, Nolen BM, Ohlson N, Zeleniuch-Jacquotte A, Lundin E (2010) Temporal reliability of cytokines and growth factors in EDTA plasma. BMC Res Notes 3: 302

Douglas JB, Silverman DT, Weinstein SJ, Graubard BI, Pollak MN, Tao Y, Virtamo J, Albanes D, Stolzenberg-Solomon RZ (2010) Serum C-reactive protein and risk of pancreatic cancer in two nested, case-control studies. Cancer Epidemiol Biomarkers Prev 20(2): 359-369

Ebrahimi B, Tucker SL, Li D, Abbruzzese JL, Kurzrock R (2004) Cytokines in pancreatic carcinoma: correlation with phenotypic characteristics and prognosis. Cancer 101(12): 2727-2736

Farrow B, Evers BM (2002) Inflammation and the development of pancreatic cancer. Surg Oncol 10(4): 153-169

Fernandez-Real JM, Broch M, Vendrell J, Ricart W (2003) Smoking, fat mass and activation of the tumor necrosis factor-alpha pathway. Int J Obes Relat Metab Disord 27(12): 1552-1556

Forsythe LK, Wallace JM, Livingstone MB (2008) Obesity and inflammation: the effects of weight loss. Nutr Res Rev 21(2): 117-133

Genkinger JM, Spiegelman D, Anderson KE, Bernstein L, van den Brandt PA, Calle EE, English DR, Folsom AR, Freudenheim JL, Fuchs CS, Giles GG, Giovannucci E, Horn-Ross PL, Larsson SC, Leitzmann M, Mannisto S, Marshall JR, Miller AB, Patel AV, Rohan TE, Stolzenberg-Solomon RZ, Verhage BA, Virtamo J, Willcox BJ, Wolk A, Ziegler RG, Smith-Warner SA (2010) A pooled analysis of 14 cohort studies of anthropometric factors and pancreatic cancer risk. Int J Cancer 29(7): 1708-1717

Goncalves RB, Coletta RD, Silvério KG, Benevides L, Casati MZ, da Silva JS, Nociti Jr FH (2011) Impact of smoking on inflammation: overview of molecular mechanisms. Inflamm Res 60(5): 409-424

Grote VA, Rohrmann S, Nieters A, Dossus L, Tjonneland A, Halkjaer J, Overvad K, Fagherazzi G, Boutron-Ruault MC, Morois S, Teucher B, Becker S, Sluik D, Boeing H, Trichopoulou A, Lagiou P, Trichopoulos D, Palli D, Pala V, Tumino R, Vineis P, Panico S, Rodriguez L, Duell EJ, Molina-Montes E, Dorronsoro M, Huerta JM, Ardanaz E, Jeurnink SM, Beulens JW, Peeters PH, Sund M, Ye W, Lindkvist B, Johansen D, Khaw KT, Wareham N, Allen N, Crowe F, Jenab M, Romieu I, Michaud DS, Riboli E, Romaguera D, Bueno-de-Mesquita HB, Kaaks R (2011) Diabetes mellitus, glycated haemoglobin and C-peptide levels in relation to pancreatic cancer risk: a study within the European Prospective Investigation into Cancer and Nutrition (EPIC) cohort. Diabetologia 54(12): 3037-3046

Gu Y, Zeleniuch-Jacquotte A, Linkov F, Koenig KL, Liu M, Velikokhatnaya L, Shore RE, Marrangoni A, Toniolo P, Lokshin AE,
Italian Association for Research on Cancer (AIRC) and National Research Council (Italy); Dutch Ministry of Public Health, Welfare and Sports (VWS), Netherlands Cancer Registry (NKR), LK Research Funds, Dutch Prevention Funds, Dutch ZON (Zorg Onderzoek Nederland), World Cancer Research Fund (WCRF), Statistics Netherlands (The Netherlands); ERC-2009AdG 232997 and Nordforsk, Nordic Centre of Excellence programme on Food, Nutrition and Health (Norway); Health Research Fund (FIS), Regional Governments of Andalucía, Asturias, Basque Country, Murcia (no. 6236) and Navarra, ISCIII RETIC (RD06/0020; Spain); Swedish Cancer Society, Swedish Scientific Council and Regional Government of Skåne and Västerbotten (Sweden); Cancer Research UK, Medical Research Council, Stroke Association, British Heart Foundation, Department of Health, Food Standards Agency, and Wellcome Trust (UK).
Arslan AA (2009) Reproducibility of serum cytokines and growth factors. Cytokine 45(1): 44-49

Haftenberger M, Lahmann PH, Panico S, Gonzalez CA, Seidell JC, Boeing H, Giurdanella MC, Krogh V, Bueno-de-Mesquita HB, Peeters PH, Skeie G, Hjartaker A, Rodriguez M, Quiros JR, Berglund G, Janlert U, Khaw KT, Spencer EA, Overvad K, Tjonneland A, Clavel-Chapelon F, Tehard B, Miller AB, Klipstein-Grobusch K, Benetou V, Kiriazi G, Riboli E, Slimani N (2002) Overweight, obesity and fat distribution in 50- to 64-year-old participants in the European Prospective Investigation into Cancer and Nutrition (EPIC). Public Health Nutr 5(6B): 1147-1162

Heikkilä K, Ebrahim S, Lawlor DA (2008) Systematic review of the association between circulating interleukin-6 (IL-6) and cancer. Eur J Cancer 44(7): 937-945

Himmerich H, Fulda S, Linseisen J, Seiler H, Wolfram G, Himmerich S, Gedrich K, Pollmacher T (2006) TNF-alpha, soluble TNF receptor and interleukin-6 plasma levels in the general population. Eur Cytokine Netw 17(3): 196-201

Hodge DR, Hurt EM, Farrar WL (2005) The role of IL-6 and STAT3 in inflammation and cancer. Eur J Cancer 41(16): 2502-2512

Hotamisligil GS (2006) Inflammation and metabolic disorders. Nature 444(7121): 860-867

Huxley R, Ansary-Moghaddam A, Berrington de González A, Barzi F, Woodward M (2005) Type-II diabetes and pancreatic cancer: a metaanalysis of 36 studies. Br J Cancer 92(11): 2076-2083

Kolb H, Mandrup-Poulsen T (2005) An immune origin of type 2 diabetes? Diabetologia 48(6): 1038-1050

Lynch SM, Vrieling A, Lubin JH, Kraft P, Mendelsohn JB, Hartge P, Canzian F, Steplowski E, Arslan AA, Gross M, Helzlsouer K, Jacobs EJ, LaCroix A, Petersen G, Zheng W, Albanes D, Amundadottir L, Bingham SA, Boffetta $\mathrm{P}$, Boutron-Ruault MC, Chanock SJ, Clipp S, Hoover RN, Jacobs K, Johnson KC, Kooperberg C, Luo J, Messina C, Palli D, Patel AV, Riboli E, Shu XO, Rodriguez Suarez L, Thomas G, Tjonneland A, Tobias GS, Tong E, Trichopoulos D, Virtamo J, Ye W, Yu K, Zeleniuch-Jacquette A, Bueno-de-Mesquita HB, Stolzenberg-Solomon RZ (2009) Cigarette smoking and pancreatic cancer: a pooled analysis from the pancreatic cancer cohort consortium. Am J Epidemiol 170(4): 403-413

McKay CJ, Glen P, McMillan DC (2008) Chronic inflammation and pancreatic cancer. Best Pract Res Clin Gastroenterol 22(1): 65-73

Moses AG, Maingay J, Sangster K, Fearon KC, Ross JA (2009) Pro-inflammatory cytokine release by peripheral blood mononuclear cells from patients with advanced pancreatic cancer: relationship to acute phase response and survival. Oncol Rep 21(4): 1091-1095

Mroczko B, Groblewska M, Gryko M, Kedra B, Szmitkowski M (2010) Diagnostic usefulness of serum interleukin 6 (IL-6) and C-reactive protein (CRP) in the differentiation between pancreatic cancer and chronic pancreatitis. J Clin Lab Anal 24(4): 256-261

Pepys MB, Hirschfield GM (2003) C-reactive protein: a critical update. J Clin Invest 111(12): 1805-1812

Raimondi S, Lowenfels AB, Morselli-Labate AM, Maisonneuve P, Pezzilli R (2010) Pancreatic cancer in chronic pancreatitis; aetiology, incidence, and early detection. Best Pract Res Clin Gastroenterol 24(3): 349-358

Riboli E, Hunt KJ, Slimani N, Ferrari P, Norat T, Fahey M, Charrondière UR, Hémon B, Casagrande C, Vignat J, Overvad K, Tjønneland A, 
Inflammation and pancreatic cancer risk VA Grote et al

Clavel-Chapelon F, Thiébaut A, Wahrendorf J, Boeing H, Trichopoulos D, Trichopoulou A, Vineis P, Palli D, Bueno-De-Mesquita HB, Peeters PH, Lund E, Engeset D, González CA, Barricarte A, Berglund G, Hallmans G, Day NE, Key TJ, Kaaks R, Saracci R (2002) European Prospective Investigation into Cancer and Nutrition (EPIC): study populations and data collection. Public Health Nutr 5(6B): 1113-1124

Talar-Wojnarowska R, Gasiorowska A, Smolarz B, Romanowicz-Makowska H, Kulig A, Malecka-Panas E (2009) Tumor necrosis factor alpha and interferon gamma genes polymorphisms and serum levels in pancreatic adenocarcinoma. Neoplasma 56(1): 56-62

Trichopoulos D, Psaltopoulou T, Orfanos P, Trichopoulou A, Boffetta P (2006) Plasma C-reactive protein and risk of cancer: a prospective study from Greece. Cancer Epidemiol Biomarkers Prev 15(2): 381-384
Vrieling A, Bueno-de-Mesquita HB, Boshuizen HC, Michaud DS, Severinsen MT, Overvad K, Olsen A, Tjonneland A, Clavel-Chapelon F, Boutron-Ruault MC, Kaaks R, Rohrmann S, Boeing H, Nothlings U, Trichopoulou A, Moutsiou E, Dilis V, Palli D, Krogh V, Panico S, Tumino R, Vineis P, van Gils CH, Peeters PH, Lund E, Gram IT, Rodriguez L, Agudo A, Larranaga N, Sanchez MJ, Navarro C, Barricarte A, Manjer J, Lindkvist B, Sund M, Ye W, Bingham S, Khaw KT, Roddam A, Key T, Boffetta P, Duell EJ, Jenab M, Gallo V, Riboli E (2010) Cigarette smoking, environmental tobacco smoke exposure and pancreatic cancer risk in the European Prospective Investigation into Cancer and Nutrition. Int J Cancer 126(10): 2394-2403

Whitcomb DC (2004) Inflammation and Cancer V. Chronic pancreatitis and pancreatic cancer. Am J Physiol Gastrointest Liver Physiol 287(2): G315-G319

This work is published under the standard license to publish agreement. After 12 months the work will become freely available and the license terms will switch to a Creative Commons Attribution-NonCommercial-Share Alike 3.0 Unported License. 